\title{
Development Status and Application of Polymer Concrete
}

\author{
Hui Li ${ }^{1}$,a, Jisi Sun ${ }^{2, b}$, Jiangbo Chen ${ }^{1}$, Shengwei Cai ${ }^{1}$, Jing Yinn ${ }^{1}$, Jianyuan $\mathrm{Xu}^{2}$ \\ ${ }^{1}$ China Electric Power Research Institute, Wuhan, 4300741 China; \\ ${ }^{2}$ School of Electrical Engineering,Shenyang University of Technology, Shenyang, 110870 China \\ a27136680@qq.com, b791837854@qq.com
}

Key words: polymer concrete; insulation material; the trend of development

\begin{abstract}
The performance of polymer concrete is excellent, which meets the requirement of environment friendly. Currently, polymer concrete is rapidly developing in the direction of high performance, low cost and ecology, but its high cost and technological complexity of features severely limit the development and application of poly concrete. There are many different kinds of polymer concrete and performance focuses on different aspects. The research relates to interdisciplinary fields which is wide and cross strong. These fields contain a slew of basic research problems. To explore the development of polymer concrete materials, this paper synthetically describe the development, performance and practical application of poly concrete. The problems existed in the production and application of polymer concrete materials are pointed out. The trend of development of poly concrete is consulted. The future research of poly concrete in insulation material is prospected. The reference for the further research and application of polymer concrete is provided.
\end{abstract}

\section{Introduction}

Concrete is widely used in engineering practice with its extensive materials, low cost and excellent mechanical properties. Although the concrete compressive strength is high, the tensile and bending strength is low, brittleness, low flexibility and dry shrinkage which seriously restrict its engineering application. To improve the performance of concrete, a small amount of organic polymer is added into the concrete to form a particulate organic/inorganic composite, greatly improve the density and brittleness of concrete, and widen the application field of concrete greatly.

The research of polymer concrete started earlier. It has been widely used in bonding, anti-corrosion, waterproof, building and laying the ground equipment, insulation etc. With the rapid development of water conservancy, transportation, machinery, electric power and other industries, polymer concrete has become an essential raw material for the production and construction, reflects great practical value.

At present, the research on the polymer concrete is mainly focus on the character of the concrete and the engineering application even the formation of the formula of the special concrete. With the continuous improvement of material requirements, the preparation process of polymer concrete is becoming more and more complex and construction conditions is demanding, the new material is low cost performance, and the service life is not a clear data assurance. To solve the above problems, domestic and foreign scholars have carried out a large number of theoretical and experimental research. In this paper, the development, performance research and application status of polymer concrete are summarized from the perspective of application. The research work of polymer concrete is prospected in service life, preparation technology, site construction and economic benefit. Research results can provide reference for the further research and application of polymer concrete. 


\section{Development, Performance and Application Situation of Polymer Concerte}

\section{Development of Polymer Concrete at Home and Abroad}

Artificial of the polymer concrete appears the earliest in the United States, in 1970s, the United States Westinghouse research and development center research on PC insulator replacement porcelain insulator and successfully developed PC insulator and used in mid-voltage field under the support of EPRI ${ }^{[1]}$. At present, polymer cement concrete bond material is mainly used styrene butadiene latex, acrylate latex. Latex mortar or latex concrete has a significant effect on the prevention of corrosion of reinforcing steel and the reduction of infiltration. Polymer concrete has also been widely used in construction projects ${ }^{[2]}$.

Polymer resin concrete materials have become the dominant building materials in Japan, Ohama Yoshihiko and others made the polymer cement concrete whose compressive strength is $2000-2800 \mathrm{kN} / \mathrm{mm}^{2}$ on the basis of the improved steam pressure concrete ${ }^{[3]}$. Polymer cement concrete has been widely used in indoor floor materials, waterproof materials, repair materials, anti-corrosion materials, deck dressing and surface layer, etc because it has some advantge such as high strength, good waterproof performance, with good adhesion and durability etc. Japan has gradually developed and improved a series of industrial standards and guidelines for polymer concrete in recent three decades ${ }^{[4]}$.

South Korean Hanhua group make a degree research through the test on basic properties of epoxy resin and different mixing ratio of unsaturated polyester resin, physical properties, mechanical properties and curing. The precast concrete sandwich panels for polymer, underground structures (such as into the hole), water pipes, electrical insulation etc. With the substantial increase in economic construction, South Korea has taken the polymer concrete as a new type of construction materials ${ }^{[5]}$.

Germany used polymer concrete to produce a variety of products such as the transformer base, hygiene products etc. At present, the database of polymer concrete ratio of German enterprises is perfect and precise. In 2013, Waibel concrete company in 2013 as many as 4000 kinds of concrete mix ratio. Waibel company in the production of concrete impermeability of concrete is first proposed according to the formulation of concrete design ideas, achieve the lowest cost, has been used in industry, polymer concrete repair, decoration and other fields ${ }^{[6]}$.

The application of polymer cement concrete has been studied in China in 1950s. Some achievements have been made in the aspects of hydraulic structures, structural repair, pavement material, corrosion resistance, anti-seismic, and so on. In recent years, polymer latex and preparation of polymer cement mortar used polyacrylic emulsion has been synthesized of the materials specifically for the production of polymer cement concrete, it is performs satisfactoy in adhesive force, waterproof, anti carbonation aging, the materials has been successfully applied to modified polymer cement mortar which used as repairing material and corrosion resistant material. But at present, the application of polymer concrete as a building material or in the power engineering is also relatively few in domestic ${ }^{[7]}$.

\section{Studies on The Properties of Polymer Concrete}

\section{1) Durability and Toughness}

In 2005, Zeqing Wang ${ }^{[8]}$ and others mixed the carboxylic styrene butadiene latex into the poly concrete to enhance its crack resistance and it showed that the crack resistance of poly concrete which is mixed with carboxylic styrene butadiene latex is greatly improved. Hongyun Yan ${ }^{[9]}$ and others found out that the mixture of carboxylic styrene butadiene styrene can decrease its bend-press ratio and largely decrease its brittleness and greatly improve its non-deformability and allowable stress. The result of the test which are demonstrated in table 1 shows that the fracture energy of the material increases with the increase of the content of styrene butadiene styrene poly. This shows that as for ordinary concrete the fracture damage of concrete modified by carboxyl styrene butadiene polymer is "flexible", and the crack growth is slow, which has good durability and toughness. 
In 2009, Yujin $\mathrm{Xu}$ and others found out that after the increase of polyer concrete's strength, while the fracture toughness, ductility, seismic performance were decreased, but its fracture energy can be improved greatly, which makes the poly concrete has a huge advantage in aspects such as raw materials ${ }^{[10]}$, process, design and application of the structure and the reduce of the cost. But for ordinary raw materials and production process of practical engineering in the preparation of poly concrete, there still has a further study on greatly increasing its fracture energy and ultimate stress without increasing the prime cost and affecting the present technics.

Table 1 Fracture properties of concrete modified by carboxyl styrene butadiene polymer

\begin{tabular}{cccc}
\hline$w_{\mathrm{p}} / \%$ & $\begin{array}{c}\text { Maximum load } \\
{\left[F_{\max } / \mathrm{kN}\right]}\end{array}$ & $\begin{array}{c}\text { fracture toughness } \\
{\left[K /\left(\mathrm{Ma}^{\mathrm{O}} \mathrm{m}^{0.5}\right)\right]}\end{array}$ & $\begin{array}{c}\text { Strain energy release } \\
{\left[\mathrm{G} /\left(\mathrm{NoM}^{-1}\right)\right]}\end{array}$ \\
\hline 0 & 5.1 & 0.43 & 139.8 \\
5 & 5.3 & 0.48 & 199.6 \\
10 & 6.4 & 0.58 & 284.0 \\
15 & 7.2 & 0.69 & 458.2 \\
\hline
\end{tabular}

\section{2) Mechanical Property}

In terms of mechanical properties, Shanxi University of science and technology combined the test and numerical simulation and studied the mechanical properties of resin concrete under static load, fracture property and other mechanical properties, which showed that the resin concrete has a great advantage in the mechanical properties. In 2015, Wuhan University of Technology had a study on the Stress, temperature and age of inorganic poly concrete. The result which is shown in table 2 and table 3 show that the compressive strength of polymer concrete is greater than the ordinary concrete. The structural parameters of inorganic polymer concrete are shown in table 4. Comparing with the ordinary concrete, the Inorganic polymer concrete's modulus of elasticity and Poisson ratio are $14.56 \%$ and $7.27 \%$ larger than the ordinary cement concrete. Inorganic poly concrete has a lower brittleness than ordinary cement concrete.

Table 2 Compressive strength of inorganic polymer concrete

\begin{tabular}{cccc}
\hline Sample & Failure load $[\mathrm{kN}]$ & Strength $[\mathrm{MPa}]$ & Average Value $[\mathrm{MPa}]$ \\
\hline Sample 1 & 970 & 43.1 & \\
Sample 2 & 1170 & 52 & 46.3 \\
Sample 3 & 985 & 43.8 & \\
\hline
\end{tabular}

Table 3 Ordinary concrete compressive strength

\begin{tabular}{cccc}
\hline Sample & Failure load $[\mathrm{kN}]$ & Strength $[\mathrm{MPa}]$ & Average Value $[\mathrm{MPa}]$ \\
\hline Sample 1 & 856.00 & 38.4 & \\
Sample 2 & 880.00 & 39.1 & 37.91 \\
Sample 3 & 823.00 & 36.59 & \\
\hline
\end{tabular}

Table 4 Ratio of inorganic polymer concrete to ordinary concrete

\begin{tabular}{cccc}
\hline & $\begin{array}{c}\text { Inorganic poly } \\
\text { concrete }\end{array}$ & ordinary concrete & The difference \\
\hline $\begin{array}{c}\text { Elastic } \\
\left.\text { modulus[N/ } / \mathrm{mm}^{2}\right]\end{array}$ & 3.58 & 3.13 & $14.56 \%$ \\
Poisson ratio & 0.236 & 0.22 & $7.27 \%$ \\
\hline
\end{tabular}

Poly types of poly concrete, preparation technology and preparation method all have a huge impact on mechanical property. With the rapid development of poly concrete to high performance, low cost and ecology, the production technology and mechanical behavior of all kinds of concrete 
must be lined into a unified standard ${ }^{[11]}$.

\section{3)Weather Resistance}

The weathering resistance of polymer concrete is influenced by the type, amount and ratio of cementing material and aggregate. After long-term outdoor exposure test, Ohama Yoshihiko thought after result calculation, the durability of polymer concrete can be guaranteed for 20 years ${ }^{[12]}$. But to determine the correct use life of different types of polymer concrete, has not yet formed complete theoretical basis, nor the formation of reliable reference data in the experiment. The accuracy of the experiment also needs to be further verified.

\section{4)Other Performance}

The electrical insulation performance of polymer concrete can reach two times of the ceramic. According to the data of PaulD.R and PowerD.w provides, the wear resistance of polymer concrete is 5-10 times that of ordinary cement concrete, anti erosion wear properties such as table 5 shows, by the data in the table can be seen, the erosion wear of polymer concrete is far less than that of the ordinary concrete. Polymer concrete also has excellent damping performance, RalPhIronman thought, the damping performance of polymer concrete is $5 \sim 6$ times higher than that of cast iron, and Koyanagi Osamu thought it can be as high as 10 20 times. The polymer concrete mixer in high viscosity, mixing requires more power.

Table 5 results of erosion wear test

\begin{tabular}{cc}
\hline Test material & 72h average wear (total weight\%) \\
\hline Ordinary cement concrete & $6.12-9.12$ \\
Methyl methacrylate concrete & 1.67 \\
Ethyl vinyl ester concrete & 0.78 \\
\hline
\end{tabular}

\section{Application of Polymer Concrete in Various Fields}

In hydraulic projects, the long-wearing strength and durability, toughness, wear resistance and higher physical and mechanical properties of the polymer concrete can be used as filling material in cement concrete pore and micro cracks, improve the density of ordinary cement concrete, enhance the cohesive force between cement and aggregate and soothe the stress at crack tip, greatly improving the structure performance of ordinary cement concrete. The polymer concrete was used in design and construction of hydraulic structures for the first time to repair the Dvorak dam's three scuppers after they were destroyed. Er jiang discharging sluic gate at gezhoubaproject pouring grades 400 concrete, shrinkage cracks appear on the surface after construction, the polymer concrete was used to repair those cracks position so that improving the anti-cavitation and anti-scouring ability of the sluice floor, this is the world's largest area of the project which engineering repair area up to $3078 \mathrm{~m}^{2}[13]$.

In transportation engineering, the polymer concrete composite has many more advantages such as a lower level of dynamic stress concentration, the compound action of road surface boundary layer is improved effectively, brittleness decreases, flexibility increases and the ratio of compressive strength and rupture strength increases and so on than that of normal cement concrete. Polymer concrete has been used for the road surface, deck paving, repair of cracks in highway maintenance, road surface cover and other engineering fields ${ }^{[14]}$. In bridge engineering, high performance concrete can effectively reduce the weight, reduce section height, reinforce structural durability, and the early strength of high performance is relatively high, greatly improve the schedule, save the construction time. Because of the high performance concrete has these features, such as higher strength, higher elastic modulus, higher tensile strength, minor creep and better durability. So, high performance concrete beams have more application value than ordinary concrete beams. And it can effectively increase the normal service life of the bridge.

In construction engineering, high strength resin tightly packed polymer concrete can increase the tensile strength, compressive strength and bending strength of the original structure can be by 3-5 times. At the same time, the features of the material that water permeability, chemical stability, 
flexibility, impact resistance are also greatly improved. At present, methyl methacrylate, unsaturated polyester styrene and acrylonitrile have been produced and put into the use of high strength corrosion resistance, wear resistance, high permeability of the construction project. However, due to the high cost, the current use is not widely ${ }^{[15]}$.

In electrical engineering, a lot of researches have been carried out in the aspects of the cable slot for the transmission project in the insulator and the high voltage transmission, due to excellent insulating properties of polymer concrete (higher than the ceramic insulator 20-50\%). In mid-voltage field, the application of PC material has been realized ${ }^{[16]}$. EPRI developed $69 \mathrm{kV}$ PC to replace the outdoor insulator porcelain insulator. ABB company also developed $72 \mathrm{kV}$ post insulator, but mainly used in the exchange of medium voltage outdoor insulation, not involving the application of ultra high voltage transmission technology. In mid-voltage field, PCC is more cost-effective than PC, with good prospects for development. But in electrical engineering, the preparation technology is higher, the processing technology is still to be improved.

In mechanical applications, the federal republic of Germany and Switzerland first use of polymer concrete instead of cast iron pedestal and bracket, 1T polymer concrete can be replaced by 4T cast iron. polymer concrete with good damping performance, low thermal conductivity, high strength, good size stability, stable performance under water and lubricating coolant and oil, it is used in the manufacture of mechanical equipment. Equipment shell made of color concrete, no longer need to be brushed color, easy to be cleaned.

\section{Conclusion}

To improve the performance of polymer concrete, expand its application areas, domestic and foreign scholars have carried out a long-term and continuous research on the mechanical properties, electrical properties, durability of polymer concrete from the material properties and engineering applications, as well as the micro level and macro level. The development of engineering materials science and technology is promoted. But there are still some problems in the following aspects, which need to be further explored by researchers.

(1) Abroad in electrical engineering, polymer concrete is applied in the insulator and the electric cable slot which has achieved good results and accumulated some experience in the operation and maintenance of equipment. At present, PCC material is used as insulation material in China. On formulation design and sample preparation for the construction of large capacity transmission pipeline, the research is still in its infancy. There are few related research literatures.

(2) There are still no reliable source of data on the service life of polymer concrete, The ratio of raw materials, construction methods, the use of conditions have a great influence on the lifetime of the material. The inner relationship is in the exploring stage. Its aging process and the end point of aging still need to be determined by type test and can not be pre judged from the theoretical point.

(3) In the aspect of production process, the special material requires higher level of preparation process. Polymer concrete has Large viscosity. Emulsion is not easy to distribute in mortar. In the preparation process it requires more fully stirring. On the raw materials, it requires the particle size is uniform, the fineness and the purity is high. In the course of construction, the water content of aggregate is tiny. It is particularly important to ensure the process of material properties.

(4) The performance of polymer concrete is better than that of ordinary concrete, and it is widely applied, but its manufacturing cost is still higher. This is still a problem that needs to be overcome how to reduce the cost on the basis of ensuring the performance of the material.

\section{Acknowledgements}

This work was financially supported by the Science and technology project of China State Grid Corporation (GY71-15-054). 


\section{Reference}

[1] Dianwen Yang, Hequan Zhu. Novel PC insulator[J]. Railway locomotive and rolling stock, 1997, 01:44-47.

[2] Han Lan, Jianxiong Chen. Preparation, construction and management of high fluidity concrete (two)[J]. Building materials in Yunnan, 1999, 03:21-25.

[3] Liantai Min. Development status and Prospect of polymer concrete and polymer cement concrete in Japan[J]. Construction technology communication (Construction Technology), 1982, 02:44-46.

[4] Keru Wu, Muhua Tan, Jingfang Chen. Summary of the Eighth International Conference on polymer concrete[J]. 1996, 05:60-63+78.

[5] Shizao Zhou, Zhiyuan Chen. Emerging material polymer concrete[J]. International academic trends , 1997 11:65-66+68.

[6] Erqing Zhang, Zhiqiang Huang. Development and application of polymer concrete[J]. Sichuan building materials, 2014, 03:39-40+43.

[7] Gang Meng, Zuoqiu Luo, Kaifeng Zhang. Review on the present situation of concrete industry and technology development in Germany[J]. Commercial concrete, 2014, 10:22-24.

[8] Yang Sun, Xiaolei Xu, Yulin Qian. Research status and development of concrete polymer composites in China[J]. Building technology, 2007, 01:12-14.

[9] Zeqing Wang. Experimental study of high damping concrete and its application in structural energy dissipation and vibration reduction[D]. Yangzhou university , 2005.

[10]Hongyun Yan, Naixing Liang, Lijun Sun, Jingyu Meng. Properties and mechanism of concrete modified by carboxyl styrene butadiene polymer $[\mathrm{J}]$. Journal of building materials , 2005, 01:30-36.

[11]Jingyu Xu, Weimin Li, Feilin Wan, Erlei Bai. Study on impact mechanical properties of geo polymer concrete[J]. 2009, 01:46-50+194.

[12]Zan Wan, Bo Zhan, Keqiang Zhang, Hongrui Meng. Research Progress on Preparation and mechanical properties of resin concrete[J]. Silicate Bulletin, 2013, 10:2079-2083.

[13]Shaoqing Huang. Performance and application of polymer concrete[J]. Chemical building materials , 1990, 01:29-33.

[14]Zhixin Jiang, Yu Tong, Application of polymer concrete[J]. Science and technology in Western China , 2008, 11:27-28.

[15]Lihui Shuai. Study on construction technology of polymer porous cement concrete colored pavement [D]. Tutor: Xu Wei. Yang Donglai. South China University of Technology, 2012.

[16]Xuming Liang, Zhaoliang Xing. Test and Research on electrical performance of insulating materials for new type of pipeline transmission[J]. Smart grid, 2016, 01:1-6.

\section{Author's brief introduction and contact information:}

Hui Li was born in China in 1982. He is a master and engineer, research direction for high voltage and insulation technology, high voltage electrical appliances, etc.

Jisi Sun was born in China in 1991. He is a master graduate student of Shenyang University of Technology. Currently, focuses on the research of high voltage and insulation test technology. 